\title{
Model Persamaan Simultan Pada Analisis Hubungan Nilai Tukar Rupiah dan Inflasi
}

\author{
Rahmadeni $^{1}$, Ririn Feronika ${ }^{2}$ \\ ${ }^{1,2}$ Program Studi Matematika, Fakultas Sains dan Teknologi, UIN Sultan Syarif Kasim Riau \\ Jl. HR. Soebrantas No. 155 Simpang Baru, Panam, Pekanbaru, 28293 \\ Email: r4dieni@gmail.com, ririnferonika95@gmail.com
}

\begin{abstract}
ABSTRAK
Model simultan merupakan pemodelan untuk beberapa persamaan yang memiliki hubungan simultan atau saling terkait. Salah satu kasus yang terdapat hubungan simultan adalah Inflasi $(I N F)$ dan Nilai Tukar (ER). Informasi tentang hubungan tersebut menjadi penting untuk mendapatkan gambaran hubungan inflasi dan nilai tukar. Oleh karena itu penelitian ini melakukan analisis untuk mendapatkan model simultan antara inflasi dan nilai tukar. Estimasi parameter yang digunakan adalah Two-Stage Least Square (2SLS). Data yang digunakan adalah data negara Indonesia pada tahun 2000-2018. Berdasarkan uji spesifikasi Hausman, diketahui bahwa nilai koefisien dari $\widehat{v}_{t}=36,49012$ artinya model INF dan ER memiliki masalah kesimultanan. Hasil uji estimasi parameter menggunakan 2SLS dengan $\alpha=5 \%$ didapatkan kesimpulan bahwa variabel yang signifikan berpengaruh terhadap inflasi adalah tingkat suku bunga, dan variabel yang signifikan berpengaruh terhadap nilai tukar adalah PDB, sementara inflasi signifikan berpengaruh terhadap nilai tukar pada $\alpha=10 \%$.
\end{abstract}

Kata kunci: Inflasi, Nilai Tukar, Simultan, Two-Stage Least Square, Uji Hausman.

\begin{abstract}
Simultaneous model is a modelling for some equation that has simultaneous correlation or related to each other. One of the cases that has simultaneous correlation is Inflation (INF) and Exchange Rate (ER). The information about this correlation becomes important to obtain the description of the correlation between inflation and exchange rate. Therefore, this research conducted an analysis to obtain the simultaneous model between inflation and exchange rate. The parameter estimation used was Two-Stage Least Square (2 SLS). Data used were the data of Indonesia in 2000-2018. Based on hausman specification test, it was known that the coefficient value of $\widehat{v_{t}}=36,49012$ which means INF and ER model has problem of simultaneosity. The result of parameter estimation test by using 2 SLS and $\alpha=5 \%$ obtains conclusion that the significant variable which has influence towards inflation is the level of interest rate, and the significant variable which has influence towards exchange rate is PDB, meanwhile inflation significantly influences exchange rate at $\alpha=10 \%$.
\end{abstract}

Keywords: Exchange Rate, Hausman Test, Inflation, Simultaneous, Two-Stage Least Square

\section{Pendahuluan}

Indonesia sebagai negara yang sedang berkembang dengan perekonomian terbuka memungkinkan penduduknya untuk memiliki akses secara penuh dalam perekonomian dunia. Pertumbuhan ekonomi merupakan salah satu indikator yang digunakan untuk mengukur keberhasilan perekonomian suatu negara. Indonesia merupakan salah satu negara berkembang yang pernah terkena dampak krisis ekonomi global. Pada tahun 2014, menurut Sukirno [8] Indonesia mengalami inflasi bukan 
hanya harga BBM yang melambung, namun harga barang-barang pokok pun ikut melambung, tingkat harga barang-barang tersebut juga dipengaruhi oleh nilai tukar Rupiah saat itu.

Ardiyanto [2] mengatakan bahwa selain inflasi terdapat juga faktor lain yang mempengaruhi perekonomian suatu negara salah satunya nilai tukar. Dalam penelitiannya Andrianus [1] mengatakan bahwa nilai tukar mata uang atau kurs merupakan salah satu variabel ekonomi makro yang sangat penting, karena pergerakan nilai kurs dapat mempengaruhi stabilitas ekonomi termasuk inflasi. Nilai tukar mata uang atau kurs merupakan salah satu cara bagi suatu negara untuk bisa bertransaksi dengan dunia luar karena dengan menggunakan kurs, transaksi dengan luar negeri dapat berjalan dengan baik.Inflasi yang tinggi atau kenaikan harga yang melonjak akan mengakibatkan terjadinya peningkatan nilai tukar mata uang Rupiah terhadap Dolar Amerika Serikat. Oleh karena itu, untuk menganalisis hubungan antara inflasi dan nilai tukar Rupiah diperlukan metode sistem persamaan simultan.

Dalam bukunya Gujarati [5] mejelaskan bahwa sistem persamaan simultan memiliki ciri-ciri terdiri dari beberapa persamaan, selain itu secara sistematis dan fenomena antar persamaan tersebut ada hubungan. Model persamaan simultan memiliki variabel endogeneous dan eksplanatori pada setiap persamaan. Variabel endogeneous pada satu persamaan dapat menjadi variabel eksplanatori pada variabel lain. Akibatnya, variabel tersebut menjadi bersifat stokastik dan berkorelasi dengan variabel eksplanatori lainnya. Dalam hal ini, estimasi Ordinary Least Square (OLS) tidak dapat digunakan. Estimasi OLS dalam sistem persamaan simultan akan menghasilkan estimasi parameter yang bias dan tidak konsisten. Beberapa alternatif estimasinya adalah The Reduced-Form Equations, Two-Stage Least Square Estimation (2SLS), Indirect Least Square (ILS), dan Three-Stage Least Squares (3SLS). Dalam bukunya Gujarati [5] menjelaskan bahwa metode 2SLS diperkenalkan oleh Theil (1953) dan Basmann (1957), metode ini masih menggunakan aplikasi Second-stage OLS. Metode 2SLS mempunyai satu estimator untuk satu parameter dan menghasilkan standard error untuk setiap estimator.

\section{Metode dan Bahan Penelitian}

\section{Model Persamaan Simultan}

Model persamaan simultan (simultaneous equation regression model) merupakan model regresi yang mempunyai lebih dari satu persamaan dan terdapat hubungan umpan balik diantara variabel, ini telah dijelaskan oleh Gujarati [6] dalam bukunya.

Model umum persamaan simultan adalah sebagai berikut :

$$
\begin{gathered}
Y_{1 t}=\beta_{12} Y_{2 t}+\beta_{13} Y_{3 t}+\cdots+\beta_{1 M} Y_{M t}+\gamma_{11} X_{1 t}+\gamma_{12} X_{2 t}+\cdots+\gamma_{1 K} X_{K t}+u_{1 t} \\
Y_{2 t}=\beta_{21} Y_{1 t}+\beta_{23} Y_{3 t}+\cdots+\beta_{2 M} Y_{M t}+\gamma_{21} X_{1 t}+\gamma_{22} X_{2 t}+\cdots+\gamma_{2 K} X_{K t}+u_{2 t} \\
\vdots \\
Y_{M t}=\beta_{M 1} Y_{1 t}+\beta_{M 2} Y_{2 t}+\cdots+\beta_{M, M-1} Y_{M-1, t}+\gamma_{M 1} X_{1 t}+\cdots+\gamma_{M 3} X_{3 t}+u_{M t}
\end{gathered}
$$

\section{Model Struktural}

Model struktural adalah model yang menggambaran struktur hubungan dari variabel-variabel ekonomi. Model struktural dari sistem persamaan pada umumnya berbentuk: 


$$
\begin{gathered}
\beta_{11} Y_{1 t}+\beta_{12} Y_{2 t}+\cdots+\beta_{1 M} Y_{M t}+\gamma_{11} X_{1 t}+\gamma_{12} X_{2 t}+\cdots+\gamma_{1 K} X_{K t}=u_{1 t} \\
\beta_{21} Y_{1 t}+\beta_{22} Y_{2 t}+\cdots+\beta_{1 M} Y_{M t}+\gamma_{21} X_{1 t}+\gamma_{22} X_{2 t}+\cdots+\gamma_{2 K} X_{K t}=u_{2 t} \\
\vdots \\
\beta_{21} Y_{1 t}+\beta_{22} Y_{2 t}+\cdots+\beta_{1 M} Y_{M t}+\gamma_{21} X_{1 t}+\gamma_{22} X_{2 t}+\cdots+\gamma_{2 K} X_{K t}=u_{2 t}
\end{gathered}
$$

\section{Uji Kesimultanan}

Uji kesimultanan pada dasarnya merupakan suatu uji yang dilakukan untuk mengetahui apakah regresor endogen berkorelasi dengan error term. Untuk menemukan situasi semacam ini menurut Gujarati [7] dapat digunakan Uji Spesifikasi Hausman.

\section{Masalah Identifikasi}

Jika taksiran koefisien persamaan struktural dapat dihasilkan dari taksiran koefisien reduced-form maka persamaan tersebut dapat dikatakan teridentifikasi atau identified, jika tidak maka persamaan tersebut dikatakan tidak teridentifikasi (unidentified) atau underidentified. Persamaan teridentifikasi terdiri dari dua tipe, yaitu exactly identified dan overidentified.

\section{Metode Estimasi (2SLS)}

Two Stage Least Squares (2SLS) digunakan untuk mengestimasi model regresi persamaan simultan yang teridentifikasikan secara berlebihan (over identified), namun juga dapat digunakan untuk yang teridentifikasi secara tepat. Metode 2SLS dilakukan dengan menggunakan Ordinary Least Square sebanyak dua kali.

Misalkan terdapat tiga persamaan simultan:

$$
\begin{aligned}
& Y_{1}=\beta_{10}+\beta_{12} Y_{2}+\beta_{13} Y_{3}+\gamma_{11} X_{1}+\gamma_{12} X_{2}+\cdots+\gamma_{1 k} X_{k}+\varepsilon_{1} \\
& Y_{2}=\beta_{20}+\beta_{11} Y_{1}+\beta_{23} Y_{3}+\gamma_{21} X_{1}+\gamma_{22} X_{2}+\cdots+\gamma_{2 k} X_{k}+\varepsilon_{1} \\
& Y_{3}=\beta_{30}+\beta_{31} Y_{1}+\beta_{32} Y_{2}+\gamma_{31} X_{1}+\gamma_{32} X_{2}+\cdots+\gamma_{3 k} X_{k}+\varepsilon_{1}
\end{aligned}
$$

Langkah 1: Membentuk model reduced-form, yaitu persamaan setiap variabel endogeneous dengan exogeneous.

$$
\begin{aligned}
& Y_{1}=\pi_{10}+\pi_{11} X_{1}+\pi_{12} X_{2}+\cdots+\pi_{1 k} X_{k}+v_{1} \\
& Y_{2}=\pi_{20}+\pi_{21} X_{1}+\pi_{22} X_{2}+\cdots+\pi_{2 k} X_{k}+v_{2} \\
& Y_{3}=\pi_{30}+\pi_{31} X_{1}+\pi_{32} X_{2}+\cdots+\pi_{3 k} X_{k}+v_{3}
\end{aligned}
$$

Langkah 2: Estimasi Persamaan $y_{1}, y_{2}$ dan $y_{3}$ pada model reduced-form langkah 1

$$
\begin{aligned}
& \hat{Y}_{1}=\hat{\pi}_{10}+\hat{\pi}_{11} X_{1}+\hat{\pi}_{12} X_{2}+\cdots+\hat{\pi}_{1 k} X_{k} \\
& \widehat{Y}_{2}=\hat{\pi}_{20}+\hat{\pi}_{21} X_{1}+\hat{\pi}_{22} X_{2}+\cdots+\hat{\pi}_{2 k} \\
& \hat{Y}_{3}=\hat{\pi}_{30}+\hat{\pi}_{31} x_{1}+\hat{\pi}_{32} x_{2}+\cdots+\hat{\pi}_{3 k} x_{k}
\end{aligned}
$$

Langkah 3:

Subtitusi nilai $\hat{Y}_{2}$ dan $\hat{Y}_{3}$ pada Persamaan $Y_{1}$

$$
Y_{1}=\beta_{10}+\beta_{12} \hat{Y}_{2}+\beta_{13} \hat{Y}_{3}+\gamma_{11} X_{1}+\gamma_{12} X_{2}+\cdots+\gamma_{1 k} X_{k}
$$

Model ini akan menghasilkan estimasi parameter persamaan $Y_{1}$.

Subtitusi nilai $\hat{Y}_{1}$ dan $\hat{Y}_{3}$ pada persamaan $Y_{2}$

$$
Y_{2}=\beta_{20}+\beta_{21} \hat{Y}_{2}+\beta_{23} \hat{Y}_{3}+\gamma_{21} X_{1}+\gamma_{22} X_{2}+\cdots+\gamma_{2 k} X_{k}
$$

Model ini akan menghasilkan estimasi parameter persamaan $Y_{2}$

Subtitusi nilai $\hat{Y}_{1}$ dan $\hat{Y}_{2}$ pada persamaan $Y_{3}$. 


$$
Y_{3}=\beta_{30}+\beta_{31} \hat{Y}_{1}+\beta_{32} \hat{Y}_{3}+\gamma_{31} X_{1}+\gamma_{32} X_{2}+\cdots+\gamma_{3 k} X_{k}
$$

Model ini akan menghasilkan estimasi parameter persamaan $Y_{3}$ [3].

\section{Uji Asumsi Klasik}

Asumsi klasik merupakan persyaratan yang harus dipenuhi pada analisis regresi berganda.Uji asumsi klasik yang biasa digunakan menurut Ghozali [4] adalah uji normalitas, uji multikolinieritas, uji heteroskedesitas dan uji autokorelasi.

\section{Hasil dan Pembahasan}

Penelitian ini menggunakan data pertahun dari tahun 2000 sampai tahun 2018, dimana data yang digunakan adalah data Inflasi (INF), Exchange Rate/Nilai Tukar Rupiah (ER), Produk Domestik Bruto (PDB), Jumlah Uang Beredar $\left(\mathrm{M}_{1}\right)$, dan Tingkat Suku Bunga (R) yang diperoleh dari Badan Pusat Statistik dan Bank Indonesia.

\section{Model Struktural}

Spesifikasi model yang digunakan dalam penelitian ini adalah:

$$
\begin{gathered}
I N F=\beta_{10}+\beta_{11} E R+\beta_{12} M_{1}+\beta_{13} R+e_{1} \\
E R=\beta_{20}+\beta_{21} I N F+\beta_{22} P D B+e_{2} .
\end{gathered}
$$

Hasil reduksi dari persamaan (15) dan (16) adalah

$$
\begin{aligned}
I N F & =\pi_{10}+\pi_{11} P D B+\pi_{12} M_{1}+\pi_{13} R+v_{t} \\
E R & =\pi_{20}+\pi_{21} P D B+\pi_{22} M_{1}+\pi_{23} R+w_{t} .
\end{aligned}
$$

\section{Uji Kesimultan (Hausman Test)}

Berdasarkan hasil uji Hausman diperoleh koefisien $\widehat{v_{t}}$ sebesar 36,49012, artinya model persamaan memiliki masalah kesimultanan.

\section{Identifikasi Masalah}

Masalah identifikasi merupakan cara yang dilakukan untuk menentukan pengestimasian model INF dan ER, identifikasi dilakukan menurut kondisi order.

Tabel 1. Identifikasi Dengan Menggunakan Kondisi Order

\begin{tabular}{|c|c|c|c|c|c|}
\hline Persamaan & $K$ & $k$ & $m$ & $m-1$ & Status Identifikasi \\
\hline 15 & 3 & 2 & 2 & 1 & Exactly Identified \\
\hline 16 & 3 & 1 & 2 & 1 & Over Identified \\
\hline
\end{tabular}

Hasil identifikasi dengan menggunakan kondisi order menunjukan bahwa kedua persamaan teridentifikasi secara exactly identified dan over identified sehingga bisa disimpulkan bahwa kita bisa menggunakan Two-Stage Least Square (2SLS).

\section{4. $\quad$ Estimasi Parameter Menggunakan Two Stage Least Square (2SLS)}

Hasil pemodelan simultan pada Model INF dan ER pada Persamaan (15) dan Persamaan (16) disajikan pada Tabel 2. 
Tabel 2. Hasil Estimasi Model Simultan dengan 2SLS

\begin{tabular}{|c|l|c|c|c|c|}
\hline Model & Variabel & Koefisien & t-hitung & $P$-value & $R$ Square \\
\hline Model 1(INF) & Konstanta & 2,923 & 0,731 & 0,477 & $66 \%$ \\
& ER & 0,002 & 0,643 & 0,531 & \\
& M1 & $-3,678 \mathrm{E}-6$ & $-1,182$ & 0,257 & \\
\hline & R & 0,740 & 2,282 & 0,039 & \\
\hline Model 2 (ER) & Konstanta & $5.621,641$ & 3,954 & 0,001 & \multirow{2}{*}{$67 \%$} \\
\hline & INF & 252,060 & 1,950 & 0,069 & \\
\cline { 1 - 4 } & PDB & 0,0004 & 5,139 & 0,000 & \\
\hline
\end{tabular}

Berdasarkan Tabel di atas maka model persamaan simultan yang diperoleh adalah:

$I N F=2,923-0,002 E R-0,0000037 M_{1}+0,740 R$

dengan $R^{2}=0,66$, dan $E R$

$$
E R=5.621,641+252,060 I N F+0,0004 P D B
$$

dengan $R^{2}=0,67$.

Pada Persamaan (19) terlihat bahwa nilai koefisien determinasi yang diperoleh adalah sebesar 0,66 dimana persamaan yang dibangun itu mampu menjelaskan perubahan variabel dependent berdasarkan variabel independent sebesar $66 \%$, sisanya dijelaskan diluar model. Sedangkan nilai koefisien determinasi yang diperoleh dari Persamaan (20) sebesar 0,67 ini artinya perubahan variabel dependent berdasarkan variabel independent sebesar $67 \%$.

Berdasarkan model persamaan simultan yang diperoleh, variabel yang signifikan berpengaruh terhadap inflasi dengan $\alpha=5 \%$ adalah tingkat suku bunga, hal ini dapat diketahui dari nilai probabilitasnya yang lebih kecil dari $\alpha$. Pada persamaan nilai tukar, variabel yang berpengaruh secara sifnifikan terhadap nilai tukar dengan $\alpha=5 \%$ adalah PDB, sementara inflasi berpengaruh pada $\alpha=10 \%$. Koefisien Inflasi dan PDB mempunyai pengaruh positif terhadap pergerakan nilai tukar di Indonesia dengan begitu dapat dikatakan bahwa apabila inflasi meningkat maka akan mengakibatkan meningkatnya nilai tukar di Indonesia, begitu juga dengan PDB.

\section{Uji Asumsi Klasik}

Selanjutnya akan dilakukan uji asumsi klasik untuk model persamaan simultan dengan tingkat signifikan $\alpha=0,05$. Uji ini dilakukan untuk mengetahui apakah model tersebut memenuhi asumsi klasik atau tidak.

\subsection{Uji Normalitas}

Uji Nomalitas yang dihasilkan berdasarkan histogram pada output Persamaan (19) diperoleh nilai probabilitas sebesar 0,45 >0,05, sedangkan pada Persamaan (20) diperoleh nilai probabilitas $0,38>0,05$, maka dapat disimpulkan asumsi kenormalan pada kedua persamaan terpenuhi.

\subsection{Uji Multikolonieritas}

Berdasarkan perhitungan, diperoleh matriks yang disajikan dalam Tabel 3 dan Tabel 4 berikut:

Tabel 3. Hasil Uji Multikolonieritas pada Persamaan (19)

\begin{tabular}{|c|c|c|c|}
\hline & ER & M1 & R \\
\hline ER & 1 & 0,840 & $-0,193$ \\
\hline M1 & 0,840 & 1 & $-0,583$ \\
\hline R & $-0,193$ & $-0,583$ & 1 \\
\hline
\end{tabular}


Tabel 4. Hasil Uji Multikolonieritas pada Persamaan (20)

\begin{tabular}{|c|c|c|}
\hline & INF & PDB \\
\hline INF & 1 & $-0,582$ \\
\hline PDB & $-0,582$ & 1 \\
\hline
\end{tabular}

Tabel 3 dan Tabel 4 menunjukan bahwa matriks yang dihasilkan tidak terdapat nilai yang lebih besar dari 0,9 sehingga dapat disimpulkan bahwa tidak terjadi multikolonieritas dalam regresi tersebut.

\section{Uji Heteroskedastisitas}

Berdasarkan output white-test, pada Persamaan (19) diperoleh nilai probabilitas obs $* R$-square 0,42 >0,05, sedangkan pada Persamaan (20) diperoleh nilai 0,08> 0,05 , sehingga dapat disimpulkan bahwa kedua persamaan tidak terdapat heteroskedastisitas.

\section{Uji Autokorelasi}

Berdasarkan output Breusch-Godfrey, pada Persamaan (19) diperoleh nilai probabilitas $o b s * R$-square $0,04<0,05$, itu artinya terdapat masalah autokorelasi pada Persamaan tersebut. Sedangkan pada Persamaan (20) diperoleh nilai 0,47 $>0,05$, sehingga dapat disimpulkan bahwa pada Persamaan (20) tidak terjadi autokorelasi.

Berdasarkan uji asumsi yang telah dilakukan, dapat disimpulkan bahwa Persamaan (19) pada model persamaan simultan yang telah di uji menggunakan $2 S L S$ yang di dapat belum memenuhi uji asumsi regresi klasik. Sedangkan model Persamaan (20) telah memenuhi syarat uji asumsi klasik.

\section{Kesimpulan}

Berdasarkan hasil uji spesifikasi Hausman diperoleh koefisien $\widehat{v_{t}}$ sebesar 36,49012, maka dapat simpulkan bahwa model persamaan memiliki masalah kesimultanan. Hasil pemodelan simultan dengan estimasi $2 S L S$ untuk inflasi adalah $I N F=2,923-0,002 E R-0,0000037 M_{1}+0,740 R$ dan nilai tukar adalah $E R=$ $5.621,641+252,060 I N F+0,0004 P D B$. Pada model $I N F$ variabel yang signifikan berpengaruh pada $\alpha=5 \%$ adalah tingkat suku bunga. Pada model $E R$, variabel yang berpengaruh secara sifnifikan terhadap nilai tukar dengan $\alpha=5 \%$ adalah PDB, sedangkan inflasi tidak signifikan berpengaruh terhadap nilai tukar pada $\alpha=5 \%$, melainkan berpengaruh pada $\alpha=10 \%$.

\section{Daftar Pustaka}

[1] Andrianus, F., Amelia dan Niko., Analisa Faktor-Faktor yang Mempengaruhi Inflasi di Indonesia Periode 1997, Ekonomi Pembangunan,11(2), 2006. 173-186.

[2] Ardiyanto, F., Ma'ruf, A., Pergerakan Nilai Tukar Rupiah Terhadap Dolar Amerika Dalam Dua Periode Penerapan Sistem Nilai Tukar. Ekonomi dan Pembangunan, 15(2), 2014. 127-134.

[3] Bekti., Rokhana, D., Model Persamaan Simultan pada Analisis Hubungan Kemiskinan dan PDRB.Comtech.5(2), 2014. 810-817. 
[4] Ghozali, Imam., Aplikasi Analisis Multivariate dengan program SPSS. Edisi Ketujuh. Semarang: Universitas Diponegoro.2013.

[5] Gujarati, D. N., Basic Economertics. Mc Graw Hill, New York. 2010.

[6] Gujarati, D. N., Dasar-Dasar Ekonometrika. Terjemahan Julius dan Yevi. Erlangga, Jakarta. 2006

[7] Sarwoko., Dasar-Dasar Ekonometrika. Andi, Yogyakarta. 2005.

[8] Sukirno, S., Makroekonomi moderni. PT. RajaGrafindoPersada, Jakarta. 2000. 